\title{
Effort of Variations of Reservoir Water Level on Landslide Stability
}

\author{
Wentao Shang ${ }^{1, a}$ and Shuai $\mathrm{Du}^{1, \mathrm{~b}}$ \\ ${ }^{1}$ Department of Architectural Engineering, Binzhou University, Binzhou, P.R. China \\ asruby2006@163.com, bgenius6844@126.com
}

Keywords: landslide; water level; variation; stability.

Abstract. Water level fluctuation will soften the rock and soil on the bank, induce the underground water fluctuated and decrease the shear strength, which will have the possibility to cause the stable slope to occur landslide. In this paper, the effort of variations of reservoir water level on landslide stability was disclosed, the buoyancy forces caused by slope partly submerged, the seepage pressure caused by water level rapid drawdown, erosion and devolution in base of the slope combined together affect the stability. The landslide seepage field under different water level conditions was stimulated through FLAC3D. Stability analysis indicates that the water level rise, the safety factor first decreases and then increases; the water level falls, the safety factor decreased gradually.

\section{Introduction}

The Three Gorges Dam across the Changjiang River in China is the biggest dam in the world. The structure stands $185 \mathrm{~m}$ tall and $2.3 \mathrm{~km}$ long. When completed, the final highest water level will be 175 $\mathrm{m}$, and the water level will fluctuate between 145 and $175 \mathrm{~m}$ (He et al. 2008). The large rise and subsequent drawdown in the water level can soften the rock and soil on the bank and decrease its resist shear strength, which will have the possibility to cause the slope instability of the reservoir bank.

The impounding a huge body of water in the reservoir is likely to make old landslides reactivate or trigger huge landslide masses. For example, a more serious incidence resulting from the impoundment of reservoir took place at the village of Qingjiangping on the Qinggan River, $3 \mathrm{~km}$ away from its confluence with the Changjiang mainstream. On the morning of July 12, 2003, 1 month just after the filling of Three Gorges Reservoir, cracks were discovered in the old Qianjiangping landslide, and then a new landslide occurred after 2 days, probably because of a combination of prolonged rainfall and reservoir impounding (Wang et al. 2004 \& Zhang et al. 2004). The impounding of water also can lead scattered in the ancient landslide. The ancient landslide in Wanzhou has five scattered in the elevation of 142 140m.

The rapid drawdown of the water level adjacent to a landslide may occur when the water level drops following a discharge stage. The groundwater level drops lag behind the reservoir water level; as a result, the landslide formed due to the pressure difference between the level of groundwater and reservoir water. Jones et al. (1961) investigated landslides that occurred in the vicinity of Roosevelt Lake in United States from 1941 to 1953. It was found that about 30\% of the landslides occurred as a result of drawing down the water level in the reservoir.

To reduce these two kinds of enormous fatalities and property losses, investigate the reason and mechanism of water level variation on the stability of the reservoir landslide may be very important. This paper disclosed the stability evolution of a landslide in Chongqing under the variation of water level.

\section{Reasons for reservoir landslide induced by water level variation}

Buoyancy forces caused by slope partly submerged. As impounding water in the reservoir, the lower parts of slope first submerged and produce buoyancy to decrease the resist force of sliding. This situation is more serious in a gentle slope because of a bigger buoyancy is produced as much area submerged in the water (fig.1). 
Seepage pressure caused by water level rapid drawdown. The groundwater level drops lag behind the reservoir water level when the reservoir water discharge after keeping high water level for a long time. The seepage pressure caused by the difference pressure between these two levels can decrease the landslide stability and trigger slide of the slopes. This situation is more serious in a small hydraulic conductivity slope (fig.2).

Erosion and devolution in base of the slope. The degree of saturation will increase and the soil shear strength decrease in the submerged conditions. The erosion and devolution in the base of the slope triggered by wave erosion in the reservoir is small-scale. But it will trigger large-scale landslide if there have an existing landslide in the above (fig.3).

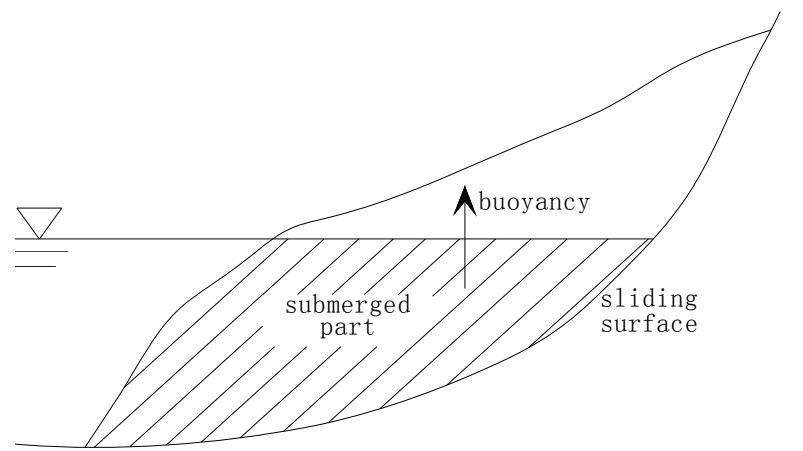

Fig. 1. The buoyancy induced by the rise of water level

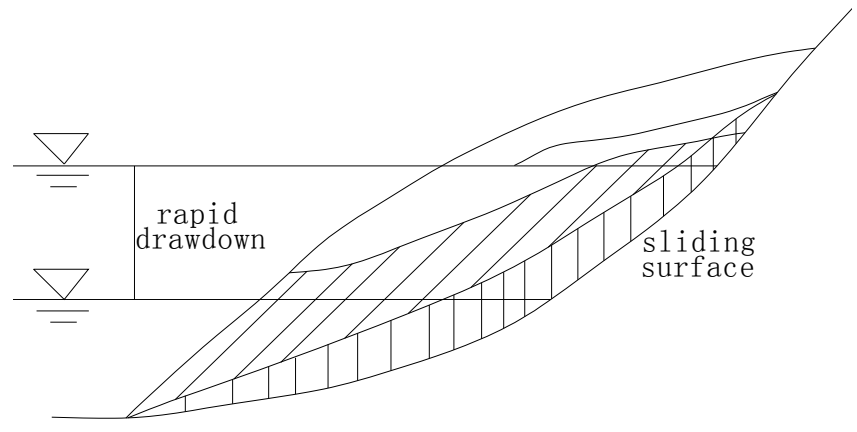

Fig. 2. Seepage pressure caused by water level rapid drawdown

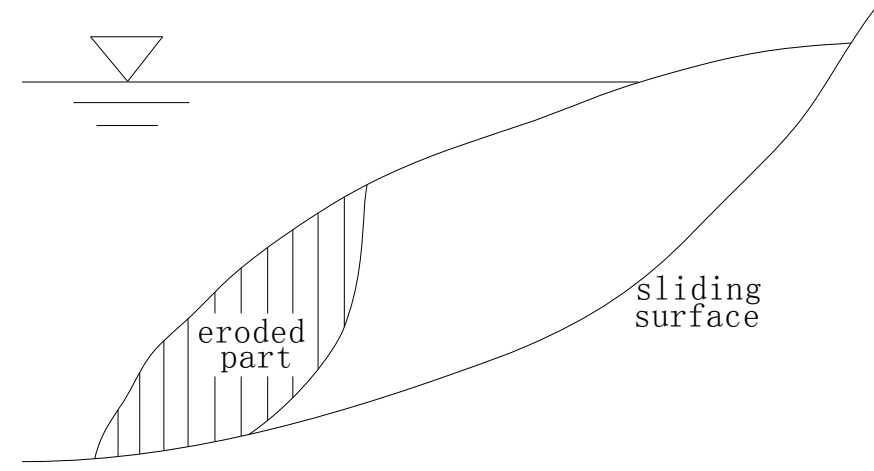

Fig 3. Erosion by impounding water or

Table 1. Physical-mechanical parameters of slide masses

\begin{tabular}{cccccc}
\hline \multicolumn{3}{c}{ Natural condition } & \multicolumn{4}{c}{ Saturated condition } \\
\hline Unit weight $\left(\mathrm{KN} / \mathrm{m}^{3}\right)$ & $\mathrm{c}(\mathrm{kpa})$ & $\varphi\left(^{\circ}\right)$ & Unit weight $\left(\mathrm{KN} / \mathrm{m}^{3}\right)$ & $\mathrm{c}(\mathrm{kpa})$ & $\varphi\left(^{\circ}\right)$ \\
20.7 & 15.5 & 12.5 & 10.9 & 11.4 & 9.3 \\
\hline
\end{tabular}

\section{Stimulate of landslide in water level variation}

The landslide is divided into three areas according the expose of bedrock (fig.4). The second area which researched in this paper located in the 145 175 water level variation, and it takes $2 / 3$ of the whole landslide.

In this paper, FLAC3D is adopted in order to trace seepage field feature of reservoir landslide when water level varies. This program called Three Dimensional Fast Lagrangian Analysis of Continua is developed by Itasca Consulting Group Inc, American (ITASCA 2000). The physical-mechanical parameters of slide masses are shown in Table 1. 


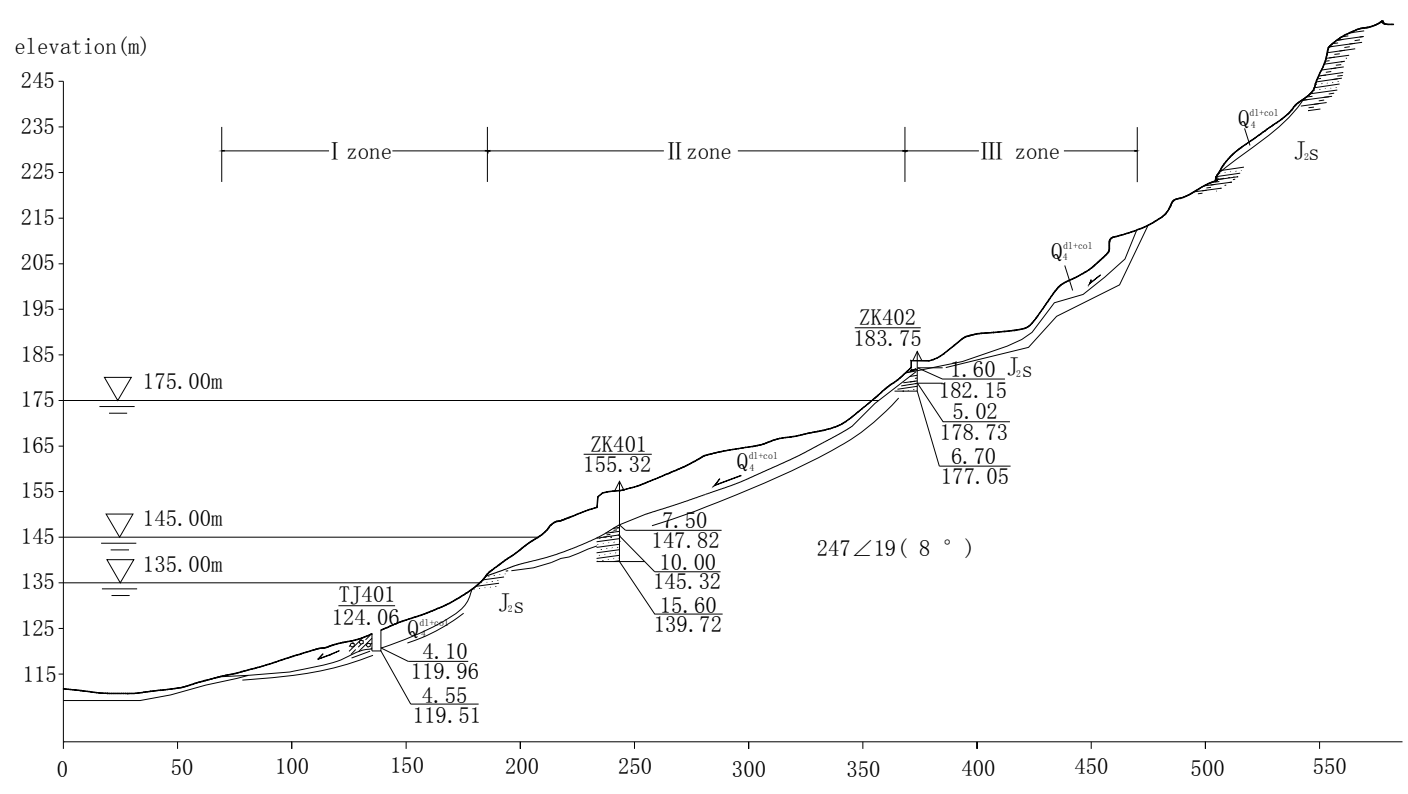

Fig 4. The profile of a landslide in Chongqing

Fig. 5 is the contour of pore pressure at $145 \mathrm{~m}$ water level. In the fluid flow analysis and calculation, the landslide is assumed as isotropy flow model. The pore water pressure is added to the landslide below the $145 \mathrm{~m}$ water level through "fix pp" command.

Fig. 6 is the contour of pore pressure at the water level increase from $145 \mathrm{~m}$ to $175 \mathrm{~m}$, the pore water pressure increases as time elapse is added to the landslide by using trigger of groundwater flow calculator. Fig. 6 shows the water in the landslide flow back as the water level increase. The direction of seepage pressure that points to the inside slope is benefit to the stability of the landslide.

Fig. 7 is the contour of pore pressure at $175 \mathrm{~m}$ water level. It is calculated as the water level at $145 \mathrm{~m}$. Fig.7 shows the contour of pore pressure is parallel to the water level and the maximum of pore pressure is in the base of the slope.

Fig. 8 is the contour of pore pressure when the water level drops from $175 \mathrm{~m}$ to $145 \mathrm{~m}$. The groundwater flow into the reservoir as the water level drops down. As time elapse, the difference of water level between the landslide and reservoir increases. This forms dynamic pressure to increase the instability of the landslide. The seepage face in the landslide forms parallel to the slide surface.

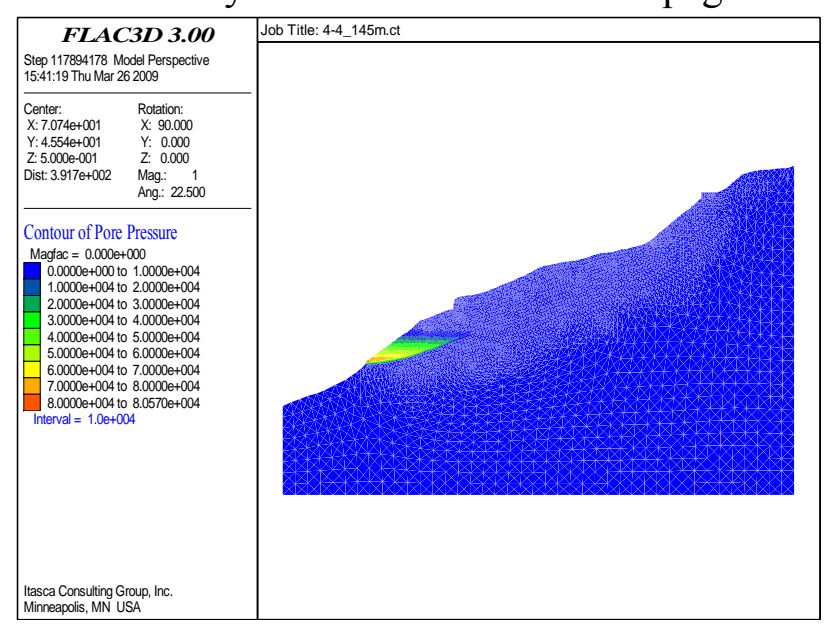

Fig. 5. The landslide seepage field at $145 \mathrm{~m}$ low stable water level

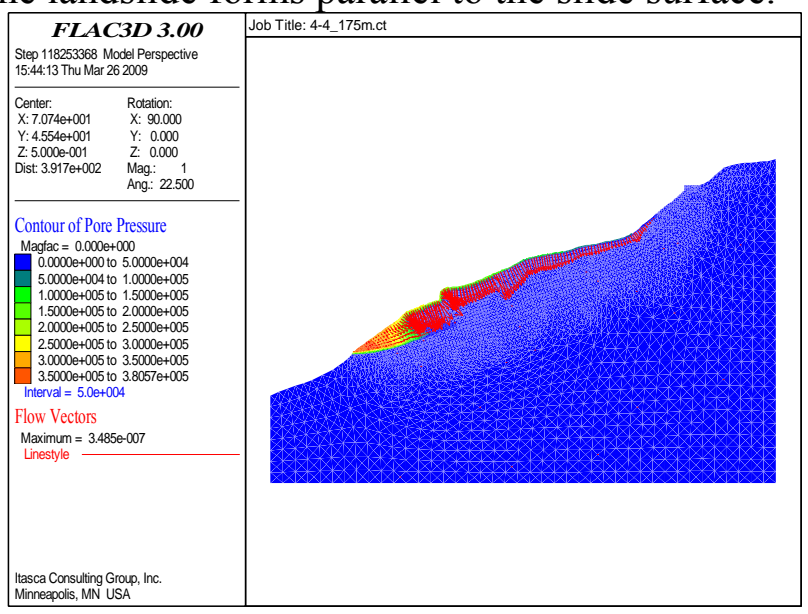

Fig. 6. The landslide seepage field when water level rises to the $175 \mathrm{~m}$ high water level 


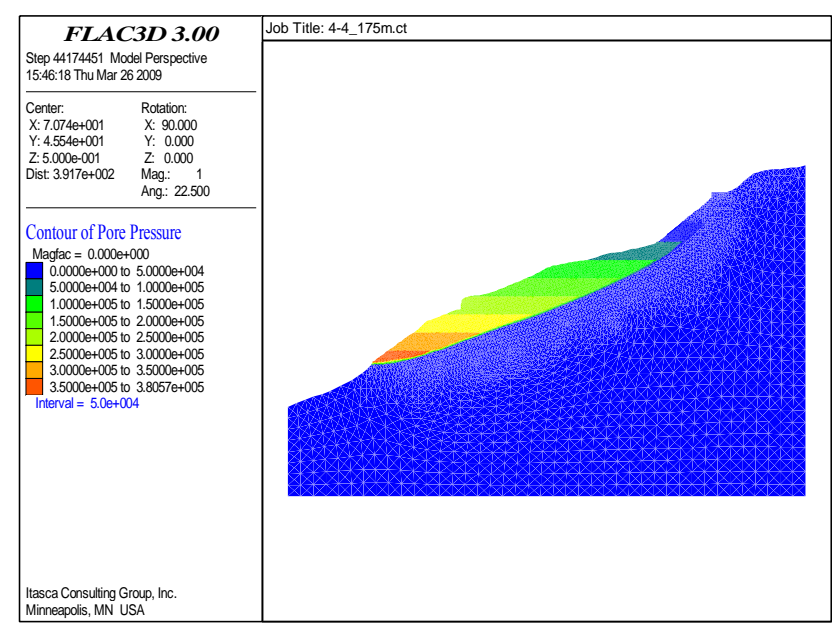

Fig. 7. The landslide seepage field at $175 \mathrm{~m}$ high stable water level

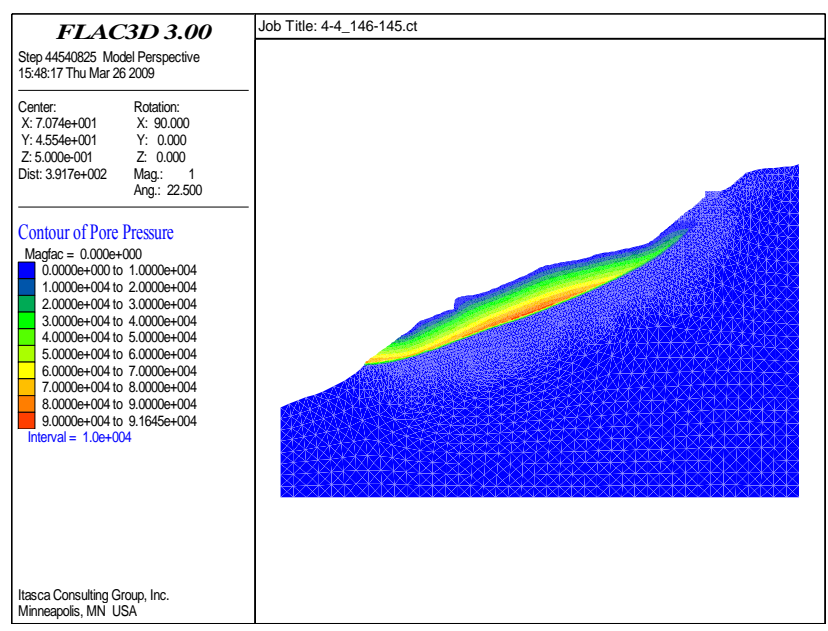

Fig. 8. The landslide seepage field when water level drops to the $145 \mathrm{~m}$ low water level

\section{Stability analyses}

Fig. 9 and Fig. 10 are the results of safety factor at different water level while reservoir running. Fig.9 shows the safety factor first decrease and subsequently increases when impounding water at the beginning level of $145 \mathrm{~m}$. The safety factors are $1.028,1.052$ at the water level of $145 \mathrm{~m}$ and $175 \mathrm{~m}$ respectively. The smallest safety factor is 0.997 at the water level of $160 \mathrm{~m}$. Fig. 10 shows the safety factor decrease from 1.036 to 0.975 continuously when reservoir discharges.

The stability evolution of the landslide is related to surface shape. The safety factor varies slowly in mild slope, and quickly in the steep slope. This is because the hydraulic gradient of hydrodynamic pressure varies by the slope surface.

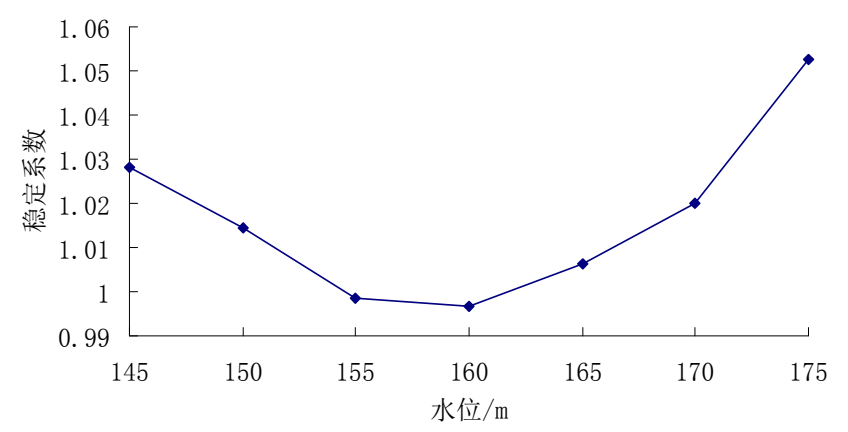

Fig 9. The landslide stability variation curve in water level rise process

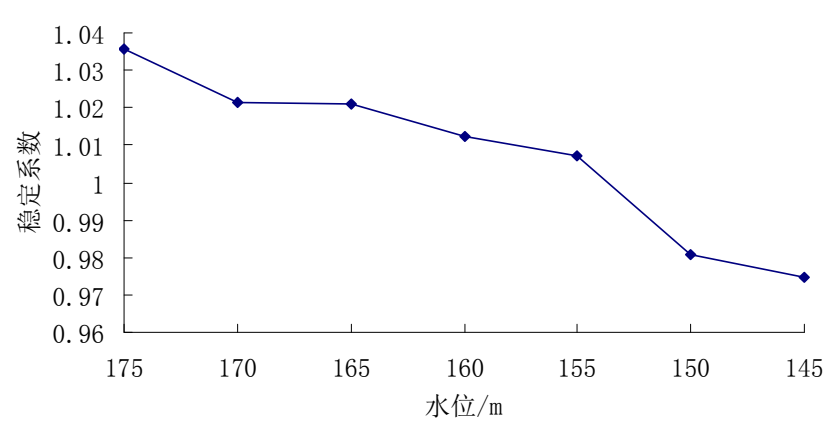

Fig 10. The landslide stability variation curve in water level drop process

\section{Conclusion}

There are many factors, such as variation of reservoir water level, shear strength and drainage coefficient, which can influence stability of reservoir landslide. Effects of reservoir water level on slope stability include the action of inter-space water pressure and the weakening of shear strength parameters of slide interface when impounding water. The safety factor first decrease and then increase as the water level increase. But the safety factor decrease gradually as the water level decrease due to the pressure difference between the level of groundwater and reservoir water. 


\section{Acknowledgements}

This work was financially supported by Shandong Provincial Natural Science Foundation, China (ZR2015PE024), Science and Technology Development Plan Project of Binzhou (2013ZC1605) and Binzhou University doctoral research funding (2013Y15).

\section{References}

[1] K.Q. He, X.R. Li and X.Q. Yan 2008: The landslides in the Three Gorges Reservoir Region, China and the effects of water storage and rain on their stability, Environmental Geology Vol. 55(2008), p. 55

[2] FLAC(Fast Lagrangian Analysis of Continua), edited by ITASCA Consulting Group. Minneapolis, $\mathrm{MN}(2000)$.

[3] F.O. Jones, D.R. Embody, W.L. Peterson: Landslides Along the Columbia River Valley, Northeastern Washington, U. S. Geological Survey Professional Paper Vol. 367(1961).

[4] F.W. Wang, Y.M. Zhang, Z.T. Huo, T Matsumoto, B.L. Huang: The July 14, 2003 Qianjiangping landslide, Three Gorges Reservoir, China, Landslide Vol. 1(2004), p. 157

[5] Y.M. Zhang, G.R. Liu, H. Chang, B.L. Huang, W. Pan: Tectonic analysis on the Qianjiangping landslide in Three Gorges Reservoir area and a revelation, Yangtze River Vol. 35(2004), p. 24 